\title{
Synthesis of oligo(lactose)-based thiols and their self-assembly onto gold surfaces
}

\author{
Timmy Fyrner, Thomas Ederth, Daniel Aili, Bo Liedberg and Peter Konradsson
}

\section{Linköping University Post Print}

\section{Tweet}

N.B.: When citing this work, cite the original article.

Original Publication:

Timmy Fyrner, Thomas Ederth, Daniel Aili, Bo Liedberg and Peter Konradsson, Synthesis of oligo(lactose)-based thiols and their self-assembly onto gold surfaces, 2013, Colloids and Surfaces B: Biointerfaces, (105), 187-193.

http://dx.doi.org/10.1016/j.colsurfb.2013.01.002

Copyright: Elsevier

http://www.elsevier.com/

Postprint available at: Linköping University Electronic Press

http://urn.kb.se/resolve?urn=urn:nbn:se:liu:diva-92697 


\section{Synthesis of Oligo(lactose)-based Thiols and Their Self-assembly onto Gold Surfaces}

Timmy Fyrner ${ }^{\mathrm{a}, *}$, Thomas Ederth ${ }^{\mathrm{b}}$, Daniel Aili ${ }^{\mathrm{b}}$, Bo Liedberg ${ }^{\mathrm{c}}$, Peter Konradsson ${ }^{\mathrm{a}}$

${ }^{a}$ Division of Chemistry, IFM, Linköping University, SE-581 83 Linköping, Sweden

${ }^{\mathrm{b}}$ Division of Molecular Physics, IFM, Linköping University, SE-581 83 Linköping, Sweden

c School of Materials Science and Engineering, Nanyang Technological University, 639798 Singapore, Singapore

* Corresponding author. Tel.: +46 13 281000; fax: +46 13281399.

E-mail: timfy@ifm.liu.se

Keywords: oligosaccharides, lactose, self-assembled monolayers, gold nanoparticles.

\section{Graphical abstract:}

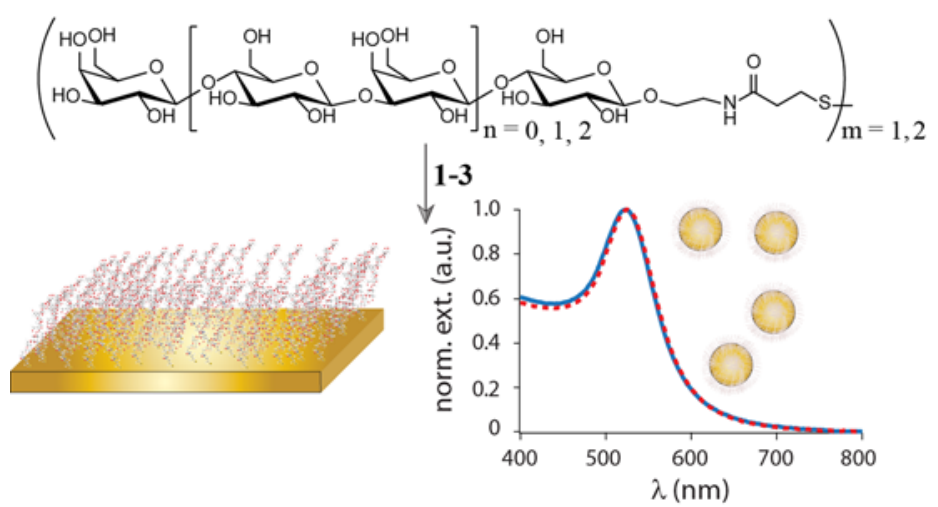




\title{
Highlights
}

Planar gold surfaces and gold nanoparticles are functionalized using oligosaccharide terminated alkanethiols. The properties of the SAMs are thoroughly characterized using infrared reflectionabsorption spectroscopy, contact angle goniometry and null-elllipsometry. The colloidal stability of the glyconanoparticles is monitored using UV-vis spectroscopy.

\begin{abstract}
The ability to produce monomolecular coatings with well-defined structural and functional properties is of key importance in biosensing, drug delivery, and many recently developed applications of nanotechnology. Organic chemistry has proven to be a powerful tool to achieve this in many research areas. Herein, we present the synthesis of three oligo(lactosides) glycosylated in a $(1 \rightarrow 3)$ manner, and which are further functionalized with amide-linked short alkanethiol spacers. The oligosaccharides (di-, tetra-, and hexasaccharide) originate from the inexpensive and readily available lactose disaccharide. These thiolated derivatives were immobilized onto gold surfaces, and the thus formed self-assembled monolayers (SAMs) on planar gold were characterized by wettability, ellipsometry and infrared reflection-absorption spectroscopy. Further, the ability of these SAMs to stabilize gold nanoparticles in saline solutions was also demonstrated, indicating that the oligosaccharides may be used as stabilizing agents in gold nanoparticle-based assays.
\end{abstract}




\section{Introduction}

Carbohydrates constitute one of the major classes of molecules found in nature, and exist in nearly every cell in the form of, for example, glycoproteins, glycolipids or other glycoconjugates.[1-3] Their molecular diversity has led to an array of different derivatives, structures and characteristics. The glycocalyx, found on external cellular membranes, is a dense surface of various glycoproteins which plays two major roles; (i) to provide sites for docking biomolecules and pathogens e.g., protecting it against the host's immune system[4] (ii) to contribute to steric repulsion, thus preventing undesirable non-specific adhesion of proteins or cells.[5] For these two functions, a prominent aspect of the glycocalyx is the carbohydrate/protein interaction.[6] Although carbohydrate/protein interactions are often weak, it is evident that they play a significant role in various biological processes, such as immune response.[7, 8]

Despite the vast abundance of carbohydrates in nature they constitute only a small part of therapeutics.[9, 10] Glyconanoparticles, that is nanoparticles coated with carbohydrates,[11] have been used to enhance transport of the nanoparticles across biological barriers and to increase their stability in biological environments.[6] Gold nanoparticles (AuNPs) used in biosensors or diagnostic assays generally require additional modification besides the one controlling the biospecificity in order to form stable colloidal dispersions. For example, functionalization with nucleic acids or proteins may destabilize AuNPs, and to improve the colloidal stability the biospecific molecule is mixed with filler molecules providing both steric stabilization and biocompatibility.[12-15] Oligo(ethylene) glycols (OEGs) are commonly used for steric stabilization of particles,[16, 17] including stabilization of liposomes used as drug delivery vehicles, where they also prevent the triggering of immune responses.[18] As an alternative, we have synthesized the oligosaccharides 1-3 (Figure 1) which presumably are rod-like[19] and 
more rigid than the flexible OEGs. The oligosaccharides consist of oligo(lactoses) glysosylated in a $(1 \rightarrow 3)$ manner.

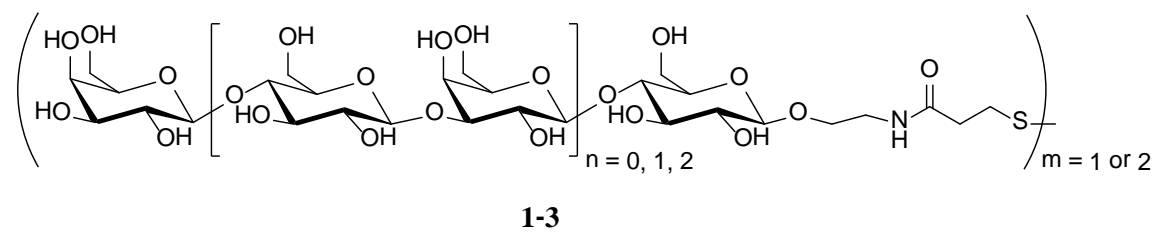

Figure 1. Synthesized oligosaccharides derived from lactose having one, two, and three lactose units.

Immobilization of thiol compounds on gold surfaces into self-assembled monolayers (SAMs) is widely used to prepare well-defined and versatile model surfaces for studies of protein adsorption and biofouling. We have earlier reported that carbohydrate-based SAMs both have proteinresistant properties comparable to those of OEGs, and that they also are highly resistant to fouling by several marine fouling species.[20-22]

In this study we present the synthesis of three oligosaccharides 1-3 (di-, tetra-, and hexa-) (Figure 1), all functionalized with a thiopropanoylic residue, starting from the corresponding fully protected oligosaccharides (di-, tetra-, and hexa-).[23] These thiols have successfully been used to form SAMs on gold surfaces and nanoparticles. Furthermore, the SAMs on planar gold were characterized by ellipsometry, contact angle goniometry and infrared reflection-adsorption spectroscopy (IRAS), and by UV-vis spectroscopy to investigate the colloidal stability of the AuNP suspensions at various salt concentrations.

\section{Materials and methods}




\subsection{General synthetic procedure}

$\mathrm{CH}_{2} \mathrm{Cl}_{2}$ was distilled over calcium hydride and collected onto predried $4 \AA$ MS. Thin layer chromatography (TLC) was carried out on Merck $60 \mathrm{~F}_{254}$ plates and visualized by UV light and/or developed with PAA [EtOH (95 vol.\%, 740 mL), $\mathrm{H}_{2} \mathrm{SO}_{4}$ (conc., 28 mL), AcOH (100 vol.\%, $8.4 \mathrm{~mL})$, p-anisaldehyde (20 mL)]. Reverse phase chromatography (RP) was carried out on Merck LiChroprep ${ }^{\circledR}$ (RP-18). Proton nuclear magnetic resonance ${ }^{1} \mathrm{H}$ were recorded on Varian (300 MHz) and carbon nuclear magnetic resonance ${ }^{13} \mathrm{C}$ was recorded on Varian $300(75.4 \mathrm{MHz})$ spectrometer (see Supporting Information); multiplicities are quoted as singlet (s), doublet (d), apparent doublet (ad), doublet of doublets (dd), triplet (t) and multiplet (m). If overlaps in carbon spectra occur this is noted. The deuterated solvent was used as internal standard for $\mathrm{CD}_{3} \mathrm{OD}\left({ }^{1} \mathrm{H}\right.$, $\left.\delta=3.31 ;{ }^{13} \mathrm{C}, \delta=49.00\right)$; for $\mathrm{D}_{2} \mathrm{O}, \mathrm{CH}_{3} \mathrm{OH}\left({ }^{1} \mathrm{H}, \delta=3.34 ;{ }^{13} \mathrm{C}, \delta=49.50\right)$ and $\mathrm{CH}_{3} \mathrm{COCH}_{3}\left({ }^{1} \mathrm{H}, \delta\right.$ $=2.22 ;{ }^{13} \mathrm{C}, \delta=30.89$ ) were used as reference.[24] Optical measurements were recorded at room temperature with a Perkin-Elmer 141 polarimeter. FT-IR was recorded on a Perkin-Elmer Spectrum 1000 using KBr pellets; appearances are quoted as strong (s), medium (m) and weak (w). Matrix assisted laser desorption ionization - Time of flight (MALDI-TOF) mass spectroscopy was recorded on a Voyager-DE STR Biochemistry Workstation, in a positive mode using 2,4,6-Trihydroxyacetophenone (THAP) as matrix. ESI-MS (recorded at Medivir AB, Huddinge, Sweden) was performed on a Water Synapt HDMS instrument equipped with electrospray interface.

\subsection{General synthetic method A}

To a solution of the fully protected glycoside $(0.659 \mathrm{~g}, 0.610 \mathrm{mmol})$ in $\mathrm{CH}_{2} \mathrm{Cl}_{2}(20$ $\mathrm{mL}$ ) was added 90 vol.\% TFA (aq.) (5 mL). After $30 \mathrm{~min}$, the mixture was diluted with $\mathrm{CH}_{2} \mathrm{Cl}_{2}$ and washed subsequently with $\mathrm{NaHCO}_{3}$ (sat. aq.), dried filtered and concentrated to give the 
deprotected diol. Without further purification the diol was dissolved in $\mathrm{CH}_{2} \mathrm{Cl}_{2} / \mathrm{MeOH}$ (30 mL, 1:2) and NaOMe (0.330 g, $6.10 \mathrm{mmol})$ was added and stirred overnight. The mixture was neutralized with Dowex $-\mathrm{H}^{+}$, filtered and concentrated. The crude deprotected compound was dissolved in $\mathrm{MeOH}$ and washed repeatedly with $n$-heptane and concentrated. The resulting compound was dissolved in $\mathrm{H}_{2} \mathrm{O}(30 \mathrm{~mL})$ and $1 \mathrm{M}$ (aq.) $\mathrm{HCl}(30 \mu \mathrm{L})$ and $\mathrm{Pd} / \mathrm{C}(10$ wt.\%) were added. The mixture was stirred overnight under $\mathrm{H}_{2}$ (g) pressure (1 atm) then filtered through Celite ${ }^{\circledR}$ and concentrated. The crude amine was dissolved in $\mathrm{H}_{2} \mathrm{O}(30 \mathrm{~mL})$ and $\mathrm{NaHCO}_{3}$ (s) (0.110 g, $1.30 \mathrm{mmol})$ and $7[25]$ (0.157 $\mathrm{g}, 0.641 \mathrm{mmol})$ was added and stirred overnight. The mixture was neutralized with Dowex $-\mathrm{H}^{+}$, filtered and concentrated. The product was purified using $\mathrm{RP}\left(\mathrm{H}_{2} \mathrm{O} \rightarrow \mathrm{H}_{2} \mathrm{O} / \mathrm{MeOH}\right.$ 1:1).

\subsection{General synthetic method $\boldsymbol{B}$}

To a solution of the thioacetylated compound $(0.120 \mathrm{~g}, 0.233 \mathrm{mmol})$ in $\mathrm{MeOH}$ (4 $\mathrm{mL}$ ) was added $\mathrm{NaOMe}(0.125 \mathrm{~g}, 0.466 \mathrm{mmol})$ followed by $\mathrm{H}_{2} \mathrm{O}(1 \mathrm{~mL})$. After $30 \mathrm{~min}$ the solution was neutralized with Dowex- $\mathrm{H}^{+}$, filtered and concentrated. The product was purified using $\mathrm{RP}\left(\mathrm{H}_{2} \mathrm{O} \rightarrow \mathrm{H}_{2} \mathrm{O} / \mathrm{MeOH} 1: 1\right)$.

2.4. Synthesis of $N$-(3-Acetyl-thio-propanoyl)-2-aminoethyl $\beta$-D-galactopyranosyl-( $1 \rightarrow 4)-\beta$ - $D$ glucopyranoside (8)

Compound 8 was synthesized as a colorless solid (0.141 g, $0.274 \mathrm{mmol}, 45 \%)$ starting from 4 using synthetic method A. $R_{f}=0.70$ (chloroform $\left./ \mathrm{MeOH} / \mathrm{H}_{2} \mathrm{O} 7: 4: 1\right) ;[\alpha]_{\mathrm{D}}+5^{\circ}$ (c 0.1, $\left.\mathrm{H}_{2} \mathrm{O}\right)$; IR (KBr) $v_{\max } \mathrm{cm}^{-1}$ : 2933 (m), $2886(\mathrm{~m}), 1687$ (s), 1651 (s), 1567 (m), 1422 (m), 1075 (s), 626 (w); ${ }^{13} \mathrm{C}-\mathrm{NMR}\left(75.4 \mathrm{MHz}, \mathrm{CD}_{3} \mathrm{OD}\right): \delta$ 25.9, 30.5, 36.6, 40.6, 61.8, 62.5, 69.6, 70.3, 72.5, 74.7, 74.7, 76.2, 76.4, 77.0, 80.7, 104.2, 105.1, 173.6, 197.2; ${ }^{1} \mathrm{H}-\mathrm{NMR}$ (300 MHz, CD $\left.{ }_{3} \mathrm{OD}\right): \delta$ 
2.31 (s, 3H), 2.50 (t, 2H, $J=7.0 \mathrm{~Hz}$ ), 3.10 (t, 2H, $J=7.0 \mathrm{~Hz}$ ), 3.24-3.34 (m, 16H), 4.32 (d, $1 \mathrm{H}, J$ = $7.8 \mathrm{~Hz}), 4.36(\mathrm{~d}, 1 \mathrm{H}, J=7.01)$; ESI-MS: $[\mathrm{M}+\mathrm{H}]^{+}$calcd for $\mathrm{C}_{19} \mathrm{H}_{33} \mathrm{NO}_{13} \mathrm{~S}$, 516.1673; found 516.1663

2.5. Synthesis of $N$-(3-thio-propanoyl)-2-aminoethyl $\quad \beta$-D-galactopyranosyl-(l $\rightarrow 4)-\beta$-Dglucopyranoside and Bis [N-2-aminoethyl- $\beta$-D-galactopyranosyl-( $1 \rightarrow 4)-\beta$-D-glucopyranosylpropanoyl] disulfide (1)

Compound 1 was synthesized as a colorless solid (99 mg, $0.21 \mathrm{mmol}, 90 \%$ ) starting from 8 using synthetic method B. $R_{f}=0.55$ (chloroform $/ \mathrm{MeOH} / \mathrm{H}_{2} \mathrm{O}$ 7:4:1); $[\alpha]_{\mathrm{D}}+4^{\circ}(\mathrm{c}$ 0.1, $\mathrm{H}_{2} \mathrm{O}$ ); IR (KBr) $v_{\max } \mathrm{cm}^{-1}: 2882(\mathrm{w}), 1655$ (m), $1650(\mathrm{~m}), 1650(\mathrm{~m}), 1562(\mathrm{w}), 1556(\mathrm{w})$, 1072 (s); NMR revealed a mixture of thiol/disulfide (1:1), inseparable in spectra for full characterization. In carbon spectra peaks are listed as they appear in the present mixture. In proton spectra, several integral values where omitted due to resolution problems. ${ }^{13} \mathrm{C}-\mathrm{NMR}$ (75.4 $\left.\mathrm{MHz}, \mathrm{D}_{2} \mathrm{O}\right): \delta$ 20.5, 34.0, 35.6, 40.0, 49.5, 60.8, 61.7, 69.1, 69.1, 69.2, 71.6, 73.2, 73.5, 74.9, 75.4, 76.0, 79.1, 79.1, 102.9, 103.6, 175, 175.1, (several overlaps occur in spectra); ${ }^{1} \mathrm{H}-\mathrm{NMR}$ (300 MHz, $\mathrm{D}_{2} \mathrm{O}$ ): $\delta 2.57$ (t, $2 \mathrm{H}, J=6.7 \mathrm{~Hz}$, thiol), 2.69 (t, $2 \mathrm{H}, J=6.8 \mathrm{~Hz}$, disulfide), 2.78 (t, 2H, $J=6.7 \mathrm{~Hz}$, thiol), 2.97 (t, 2H, $J=6.8 \mathrm{~Hz}$, disulfide), 3.30-3.82 (m), 3.91-3.99 (m), 4.42-4.45 (m), $4.49(\mathrm{~d}, \mathrm{~J}=7.9 \mathrm{~Hz}), 4.50(\mathrm{~d}, \mathrm{~J}=7.7 \mathrm{~Hz})$; MALDI-TOF (THAP): $[\mathrm{M}+\mathrm{Na}]^{+}$calcd for $\mathrm{C}_{17} \mathrm{H}_{31} \mathrm{NO}_{12} \mathrm{~S}$, 496.16; found 496.10; ESI-MS: $[\mathrm{M}+\mathrm{H}]^{+}$calcd for $\mathrm{C}_{34} \mathrm{H}_{60} \mathrm{~N}_{2} \mathrm{O}_{24} \mathrm{~S}_{2}$, 945.2978; found 945.2948 .

2.6. Synthesis of $N$-(3-Acetyl-thio-propanoyl)-2-aminoethyl $\beta$-D-galactopyranosyl-(1 $1 \rightarrow 4)-\beta$-Dglucopyranosyl-(1 $\rightarrow 3)-\beta$-D-galactopyranosyl-( $(1 \rightarrow 4)-\beta$-D-glucopyranoside (9) 
Compound 9 was synthesized as a colorless solid (0.175 g, $0.208 \mathrm{mmol}, 43 \%$ ) starting from 5 using synthetic method A. $R_{f}=0.30$ (chloroform $/ \mathrm{MeOH} / \mathrm{H}_{2} \mathrm{O}$ 7:4:1); $[\alpha]_{\mathrm{D}}+10^{\circ}$ (c 0.1, $\mathrm{H}_{2} \mathrm{O}$ ); IR (KBr) $v_{\max } \mathrm{cm}^{-1}$ : 2882 (m), 1687 (m), 1556 (w), 1074 (s), 623 (w); NMR: ${ }^{13} \mathrm{C}$ (75.4 MHz, $\left.\mathrm{D}_{2} \mathrm{O}\right): \delta$ 25.5, 30.6, 35.8, 39.9, 60.5, 60.7, 61.6, 61.6, 68.9, 69.1, 69.2, 70.7, 71.6, 73.2, 73.4, 73.6, 74.8, 74.9, 75.2, 75.4, 75.6, 76.0, 78.7, 78.9, 82.7, 102.9, 103.2, 103.5, 104.2, 174.8, 201.5; ${ }^{1} \mathrm{H}\left(300 \mathrm{MHz}, \mathrm{D}_{2} \mathrm{O}\right): \delta 2.26$ (s, 3H), 2.46 (t, 2H, $\left.J=6.9 \mathrm{~Hz}\right), 3.02$ (t, $2 \mathrm{H}, J=6.9$ Hz), 3.21-3.79 (m, 23H), 3.81-3.90 (m, 4H), 4.09 (ad, 1H, $J=3.1 \mathrm{~Hz}), 4.34$ (d, 1H, $J=7.7 \mathrm{~Hz})$, 4.38 (d, 1H, $J=7.9 \mathrm{~Hz}), 4.39$ (d, 1H, $J=7.7 \mathrm{~Hz}), 4.59$ (d, 1H, $J=8.0 \mathrm{~Hz}$ ); ESI-MS: $[\mathrm{M}+\mathrm{H}]^{+}$ calcd for $\mathrm{C}_{31} \mathrm{H}_{53} \mathrm{NO}_{23} \mathrm{~S}$, 840.2729; found 840.2693.

2.7. Synthesis of Bis [N-2-aminoethyl $\beta$-D-galactopyranosyl-( $1 \rightarrow 4)-\beta$-D-glucopyranosyl-( $1 \rightarrow 3)$ $\beta$-D-galactopyranosyl-( $1 \rightarrow 4)$ - $\beta$-D-glucopyranosyl-propanoyl] disulfide (2)

Compound 2 was synthesized as a colorless solid (95 mg, $0.12 \mathrm{mmol}, 88 \%$ ) starting from 9 using synthetic method B. $R_{f}=0.20$ (chloroform $/ \mathrm{MeOH} / \mathrm{H}_{2} \mathrm{O}$ 7:4:1); $[\alpha]_{\mathrm{D}}+10^{\circ}$ (c 0.1, $\left.\mathrm{H}_{2} \mathrm{O}\right)$; IR (KBr) $v_{\max } \mathrm{cm}^{-1}$ : $2886(\mathrm{~m}), 1650$ (m), 1562 (m), 1073 (s); NMR: ${ }^{13} \mathrm{C}(75.4 \mathrm{MHz}$, $\left.\mathrm{D}_{2} \mathrm{O}\right): \delta 33.9,35.6,40.0,60.5,60.7,61.6,61.6,68.9,69.1,69.2,70.7,71.6,73.2,73.4,73.6,74.8$, 74.9, 75.2, 75.4, 75.6, 76.0, 78.7, 78.9, 82.7, 102.9, 103.2, 103.5, 104.2, 175.0; ${ }^{1} \mathrm{H}(300 \mathrm{MHz}$, $\left.\mathrm{CDCl}_{3}\right): \delta 2.69(\mathrm{t}, 4 \mathrm{H}, J=6.8 \mathrm{~Hz}), 2.97(\mathrm{t}, 4 \mathrm{H}, J=6.8 \mathrm{~Hz}), 3.30-4.00(\mathrm{~m}, 54 \mathrm{H}), 4.18(\mathrm{ad}, 2 \mathrm{H}, J=$ $2.9 \mathrm{~Hz}), 4.45$ (d, 2H, $J=7.7 \mathrm{~Hz}), 4.48-4.51$ (m, 4H), 4.70 (d, 2H, $J=8.0 \mathrm{~Hz})$; ESI-MS: [M + H] calcd for $\mathrm{C}_{58} \mathrm{H}_{100} \mathrm{~N}_{2} \mathrm{O}_{44} \mathrm{~S}_{2}, 1592.5091$; found 1592.5167.

2.8. Synthesis of $N$-(3-Acetyl-thio-propanoyl)-2-aminoethyl $\beta$-D-galactopyranosyl-(1 $\rightarrow 4)-\beta$ - $D$ glucopyranosyl-( $1 \rightarrow 3)-\beta$-D-galactopyranosyl- $(1 \rightarrow 4)$ - $\beta$-D-glucopyranosyl- $(1 \rightarrow 3)-\beta$ - $D$ galactopyranosyl-( $1 \rightarrow 4)-\beta$-D-glucopyranoside $(\mathbf{1 0})$ 
Compound 10 was synthesized as a colorless solid (79 mg, $68 \mu \mathrm{mol}, 41 \%$ ) starting from 6 using synthetic method A. $R_{f}=0.20$ (chloroform $/ \mathrm{MeOH} / \mathrm{H}_{2} \mathrm{O}$ 7:4:1); $[\alpha]_{\mathrm{D}}+7^{\circ}$ (c 0.1 , $\mathrm{H}_{2} \mathrm{O}$ ); IR (KBr) $v_{\max } \mathrm{cm}^{-1}$ : $2886(\mathrm{~m}), 1656(\mathrm{~m}), 1562$ (w), $1074(\mathrm{~s}), 625(\mathrm{w})$; NMR: ${ }^{13} \mathrm{C}(75.4$ MHz, $\left.\mathrm{D}_{2} \mathrm{O}\right): \delta$ 25.5, 30.6, 35.8, 39.9, 60.5, 60.7, 61.5, 61.6, 68.9, 69.1, 69.2, 70.7, 71.6, 73.2, 73.5, 73.6, 74.8, 74.9, 75.2, 75.4, 75.6, 76.0, 78.5, 78.7, 78.9, 82.7, 102.9, 103.2, 103.2, 103.6, 104.2, 104.2, 174.8, 201.5, (several overlaps occur in spectra); ${ }^{1} \mathrm{H}\left(300 \mathrm{MHz}, \mathrm{CDCl}_{3}\right): \delta 2.37$ (s, 3H), 2.57 (t, 2H, $J=6.7 \mathrm{~Hz}), 3.12$ (t, 2H, $J=6.7 \mathrm{~Hz}), 3.32-3.84(\mathrm{~m}, 33 \mathrm{H}), 3.91-4.01$ (m, 5H), 4.18-4.19 (m, 2H), 4.45 (d, 1H, $J=7.7 \mathrm{~Hz}), 4.49$ (d, 1H, $J=7.6 \mathrm{~Hz}), 4.50$ (d, 1H, $J=7.7 \mathrm{~Hz})$, $5.51(\mathrm{~d}, 1 \mathrm{H}, J=7.6 \mathrm{~Hz}), 4.67-4.71(\mathrm{~m}, 2 \mathrm{H})$; ESI-MS: $[\mathrm{M}+\mathrm{H}]^{+}$calcd for $\mathrm{C}_{43} \mathrm{H}_{73} \mathrm{NO}_{33} \mathrm{~S}$, 1164.3786; found 1164.3799.

2.9. Synthesis of $\quad[N$-(3-thio-propanoyl)-2-aminoethyl $\quad \beta$-D-galactopyranosyl-( $1 \rightarrow 4)-\beta$ - $D$ glucopyranosyl-( $1 \rightarrow 3)$ - $\beta$-D-galactopyranosyl-( $1 \rightarrow 4)$ - $\beta$-D-glucopyranosyl- $(1 \rightarrow 3)-\beta$-D-

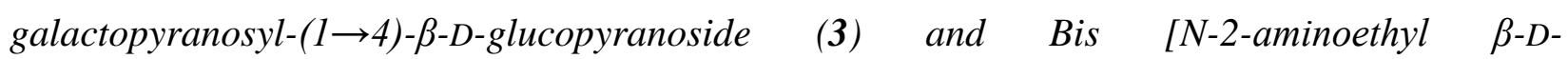
galactopyranosyl-( $1 \rightarrow 4)$ - $\beta$-D-glucopyranosyl-( $(\rightarrow 3)$ - $\beta$-D-galactopyranosyl- $(1 \rightarrow 4)-\beta$ - $D$ -

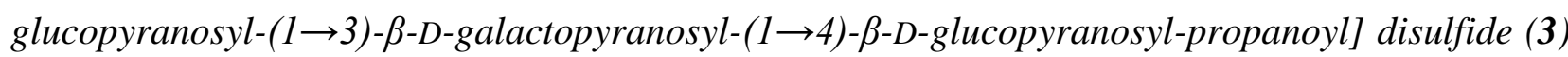
Compound 3 was synthesized as a colorless solid (20 mg, $18 \mu \mathrm{mol}, 85 \%$ ) starting from 10 using synthetic method B. $R_{f}=0.05$ (chloroform $/ \mathrm{MeOH} / \mathrm{H}_{2} \mathrm{O} 7: 4: 1$ ); $[\alpha]_{\mathrm{D}}+8^{\circ}$ (c 0.1 , $\left.\mathrm{H}_{2} \mathrm{O}\right)$; IR (KBr) $v_{\max } \mathrm{cm}^{-1}$ : $2882(\mathrm{~m}), 1656(\mathrm{~m}), 1562(\mathrm{w}), 1074(\mathrm{~s})$; NMR revealed a mixture of thiol/disulfide (4:3), inseparable in spectra for full characterization. In carbon spectra peaks are listed as they appear in the present mixture. In proton spectra, several integral values are omitted due to resolution problems. NMR: ${ }^{13} \mathrm{C}\left(75.4 \mathrm{MHz}, \mathrm{D}_{2} \mathrm{O}\right): \delta 33.9,35.6,39.9,40.1,60.5,60.7,61.6$, 61.6, 68.9, 69.1, 69.2, 70.7, 71.6, 73.2, 73.5, 73.6, 74.8, 74.9, 75.2, 75.4, 75.6, 76.0, 78.6, 78.7, 78.9, 78.9, 82.7, 102.9, 103.2, 103.2, 103.5, 104.2, 175.0, 175.2 (several overlaps occur in 
spectra); ${ }^{1} \mathrm{H}\left(300 \mathrm{MHz}, \mathrm{CDCl}_{3}\right): \delta 2.56(\mathrm{t}, 2 \mathrm{H}, J=6.7 \mathrm{~Hz}$, thiol), $2.69(\mathrm{t}, 2 \mathrm{H}, J=6.6 \mathrm{~Hz}$, disulfide), 2.78 (t, 2H, $J=6.7 \mathrm{~Hz}$, thiol), 2.97 (t, 2H, $J=6.6 \mathrm{~Hz}$, disulfide), 3.27-3.84 (m), 3.924.00 (m), 4.43-4.51 (m), 4.65-4.68 (m); MALDI-TOF (THAP): $[\mathrm{M}+\mathrm{Na}]^{+}$calcd for $\mathrm{C}_{41} \mathrm{H}_{71} \mathrm{NO}_{32} \mathrm{~S}$, 1144.37; found 1144.20; MALDI-TOF (THAP): $[\mathrm{M}+\mathrm{Na}]^{+}$calcd for $\mathrm{C}_{82} \mathrm{H}_{140} \mathrm{~N}_{2} \mathrm{O}_{64} \mathrm{~S}_{2}$, 2263.72; found 2263.61.

\subsection{SAM preparation}

SAMs were prepared on gold coated pieces of silicon wafers. A wafer was cut into $40 \times 20 \mathrm{~mm}^{2}$ pieces, cleaned in a mixture of $\mathrm{H}_{2} \mathrm{O}, 30$ vol.\% $\mathrm{H}_{2} \mathrm{O}_{2}$ and 25 vol.\% $\mathrm{NH}_{3}$ in a 5:1:1 volume ratio, at $80 \mathrm{C}$ for $10 \mathrm{~min}$ (TL1-cleaning), rinsed with Milli-Q (MQ) water, and then blown dry with nitrogen gas. The pieces were mounted in a custom-built electron-beam evaporation system with a base pressure of about $10^{-9}$ Torr, where a $25 \AA$ Ti layer was deposited immediately before a 2000 Å gold layer. After evaporation, the gold-coated pieces were TL1cleaned before $24 \mathrm{~h}$ incubation in $100 \mu \mathrm{M}$ aqueous solutions of the oligosaccharides. After incubation, the SAMs were rinsed with water, sonicated for 2 min, rinsed again and finally dried before being the physical characterization by IRAS, ellipsometry or contact angle goniometry.

\subsection{Contact angle measurements of SAMs}

A semi-automatic optical contact angle meter (KSV CAM 200) was used to determine advancing and receding contact angles of water on the SAMs. Contact angles were obtained from drop shape analysis of video recordings of manually expanded or retracted sessile droplets.

\subsection{Ellipsometry measurements of SAMs}


A Rudolph Research AutoEL ellipsometer with a $70^{\circ}$ angle of incidence and a HeNe laser $(632.8 \mathrm{~nm})$ as the light source was used for thickness measurements of the SAMs. A three-layer optical model (ambient/organic film/gold) and a refractive index of 1.5 for the organic layer were used to model the SAM.

\subsection{Infrared reflection-absorption spectroscopy (IRAS) of SAMs}

Fourier-transform IRAS measurements were performed using a grazing angle (85) reflection setup (Bruker IFS66) with a $\mathrm{LN}_{2}$-cooled MCT detector and continuous $\mathrm{N}_{2}$ purging. 3000 scans were acquired (about $10 \mathrm{~min}$ ) at $2 \mathrm{~cm}^{-1}$ resolution, and a three-term BlackmannHarris apodization was applied to the interferograms before Fourier transformation. Background spectra were recorded using gold substrates with a per-deuterated hexadecanethiol SAM. The bulk IR spectrum was obtained by pressing a tablet from $1 \mathrm{mg} 2$ and $300 \mathrm{mg} \mathrm{KBr}$, and averaging 200 transmission interferograms at $4 \mathrm{~cm}^{-1}$ resolution.

\subsection{Gold nanoparticle synthesis, functionalization and characterization}

Gold nanoparticles with an approximate average diameter of $\sim 15-\mathrm{nm}$ were obtained by citrate reduction of $\mathrm{HAuCl}_{4}$. All glassware was cleaned in a TL1 and thoroughly rinsed with MilliQ water $(18.2 \mathrm{M} \Omega \mathrm{cm})$ before use. $50 \mathrm{~mL}$ of an aqueous solution of $1 \mathrm{mM}$ $\mathrm{HAuCl}_{4}$ were brought to a reflux while stirring. $5 \mathrm{~mL}$ of $38.8 \mathrm{mM}$ trisodium citrate were added rapidly, and the solution was refluxed for an additional 15 min while stirring vigorously. The color changed from pale yellow to deep red, and the suspension was thereafter allowed to cool to room temperature. The UV-vis spectra showed a sharp and characteristic plasmon band with a maximum at approximately $520 \mathrm{~nm}$. The size and monodispersity of the nanoparticles were determined using electron microscopy. 
Compounds $\mathbf{1}, \mathbf{2}, \mathbf{3}$, were added to the gold sols and incubated for $12 \mathrm{~h}$ at $4{ }^{\circ} \mathrm{C}$. The particles were repeatedly centrifuged at $18000 \mathrm{~g}$ for $15 \mathrm{~min}$ and redispersed in $10 \mathrm{mM}$ phosphate buffer, 140 $\mathrm{mM} \mathrm{NaCl}$ (PBS) in order to remove unbound molecules.

UV-vis spectroscopy was carried out on a Schimadzu UV-1601PC spectrophotometer with 0.5$\mathrm{nm}$ resolution at room temperature.

\section{Result and discussion}

\subsection{Oligosaccharide Synthesis}

The synthesis of target compounds 1-3 were performed as depicted in Scheme 1, starting from the synthesized lactosides 4-6.[23] The isopropylidene acetal was deprotected using TFA (90 vol.\%, (aq.)) followed by a debenzoylation with $\mathrm{NaOMe} \mathrm{in} \mathrm{MeOH}$ and a subsequent hydrogenation using Pd/C (10 wt.\%) as catalyst. The crude amine was then coupled with 3(acetyl-thio)propionic acid $N$-succinimidyl ester 7[25] in $\mathrm{H}_{2} \mathrm{O}$ giving compound 8-10 in 41-45\% yield over four steps. In order to avoid deprotection of the S-acetyl group during the evaporation, giving mixtures of -SAc, -SH and -S-S-, it was found that the amide coupling reaction had to be quenched with Dowex- $\mathrm{H}^{+}$. The final deacetylation was accomplished using $\mathrm{NaOMe}$ in $\mathrm{MeOH} / \mathrm{H}_{2} \mathrm{O}(4: 1)$ to give the target compounds $\mathbf{1 - 3}$ in $85-90 \%$ yields. 


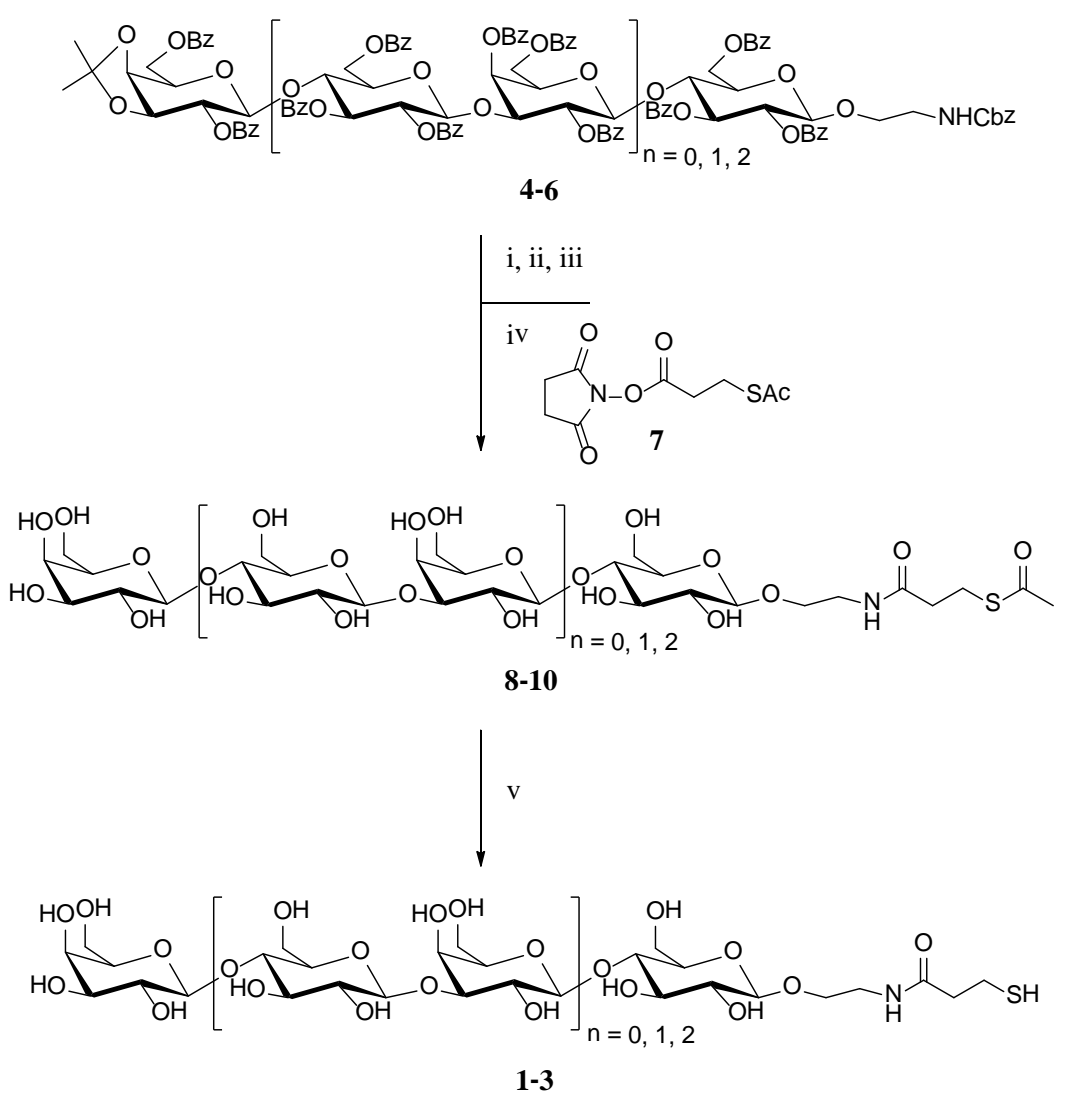

Scheme 1. Reagents and conditions: (i) TFA (90 vol.\%, (aq.)), $\mathrm{CH}_{2} \mathrm{Cl}_{2}$; (ii) $\mathrm{NaOMe}, \mathrm{MeOH}$; (iii) Pd/C (10 wt.\%), 1 M HCl, $\mathrm{H}_{2} \mathrm{O}$; (iv) 7[25], $\mathrm{NaHCO}_{3}, \mathrm{H}_{2} \mathrm{O}$; (v) NaOMe, $\mathrm{MeOH} / \mathrm{H}_{2} \mathrm{O}$ (4:1).

\subsection{Characterization of SAMs}

The advancing contact angles for the three SAMs are all $<10$ degrees (receding angles are all zero), demonstrating that the SAMs formed from 1-3 are very hydrophilic, as would be expected for the highly hydroxylated oligosaccharide moieties, and in agreement with previous results for mono- and oligosaccharide SAMs.[20-22] The ellipsometric thicknesses (Table 1) vary in a non-intuitive manner, since the thickness difference between $\mathbf{1}$ and $\mathbf{2}$ is smaller than that between 2 to 3 (5.2 $\AA$ and $8.9 \AA$, respectively), although the nominal length differences between the molecules are identical. This observation is discussed further down, in conjunction with the IRAS results. 
Table 1. Ellipsometric thicknesses, and relative IRAS intensities in the fingerprint region for the three oligosaccharides 1-3.

\begin{tabular}{llll} 
& $\begin{array}{l}\text { Ellipsometric } \\
\text { thickness } \\
(\AA)\end{array}$ & $\begin{array}{l}\text { Relative } \\
\text { intensity } \\
\text { (a.u.) }\end{array}$ & IRAS \\
\hline $\mathbf{1}$ & $15.7 \pm 0.2$ & 0.43 & \\
$\mathbf{2}$ & $20.9 \pm 0.2$ & 0.61 & \\
$\mathbf{3}$ & $29.8 \pm 0.2$ & 1 & \\
\hline
\end{tabular}

\subsubsection{IRAS: the $C-H$ stretching region}

The C-H stretching vibrations over $2800-3000 \mathrm{~cm}^{-1}$ in IRAS spectra (Figure 2) are often used to infer information about the conformation and organization or molecular packing of alkyl chains in alkylthiol SAMs. The frequencies of the symmetric $\left(v_{\mathrm{s}}\right)$ and asymmetric $\left(v_{\mathrm{as}}\right)$ $\mathrm{CH}_{2}$ stretching modes are used to distinguish between all-trans (crystalline-like) and gauche-rich (liquid-like) chain conformations. As order decreases, both $\mathrm{CH}_{2}$ modes shift to higher frequencies (for a crystalline alkyl chain the $v_{\mathrm{s}}$ and $v_{\text {as }}$ modes appear near 2850 and $2918 \mathrm{~cm}^{-1}$, respectively, but shift to 2856 and $2928 \mathrm{~cm}^{-1}$ for liquid-like chains) In this case, however (Figure 2), the $\mathrm{CH}_{2}$ modes have contributions from both methylene units in the amide-containing spacer between the thiol and the saccharide moieties, and from methylene units in the saccharide groups. The $v_{\mathrm{s}}$ contributions appear as a barely distinguishable shoulder above $2850 \mathrm{~cm}^{-1}$, whose exact position is very difficult to establish because of a strong absorption at about $2890 \mathrm{~cm}^{-1}$. This latter absorption is presumably originating from $\mathrm{CH}_{2}$ and $\mathrm{CH}$ vibrations in the sugar methylene units.

For the asymmetric vibrations the dominating absorption appears at $2924-2932 \mathrm{~cm}^{-1}$, and it is the contribution from both the alkyl spacer and the saccharide moieties. A weaker shoulder is also 
seen at about $2960 \mathrm{~cm}^{-1}$. Contrary to the situation for many other alkylthiol SAMs, the peak pattern in the $\mathrm{CH}$ region does not permit a clear interpretation in terms of the order of the alkyl chains, in this case. Considering the very bulky saccharide groups, which prevent close packing of the alkyl segments into a crystalline structure, a certain degree of disorder in the linker segments is expected, as has been demonstrated previously.[22]

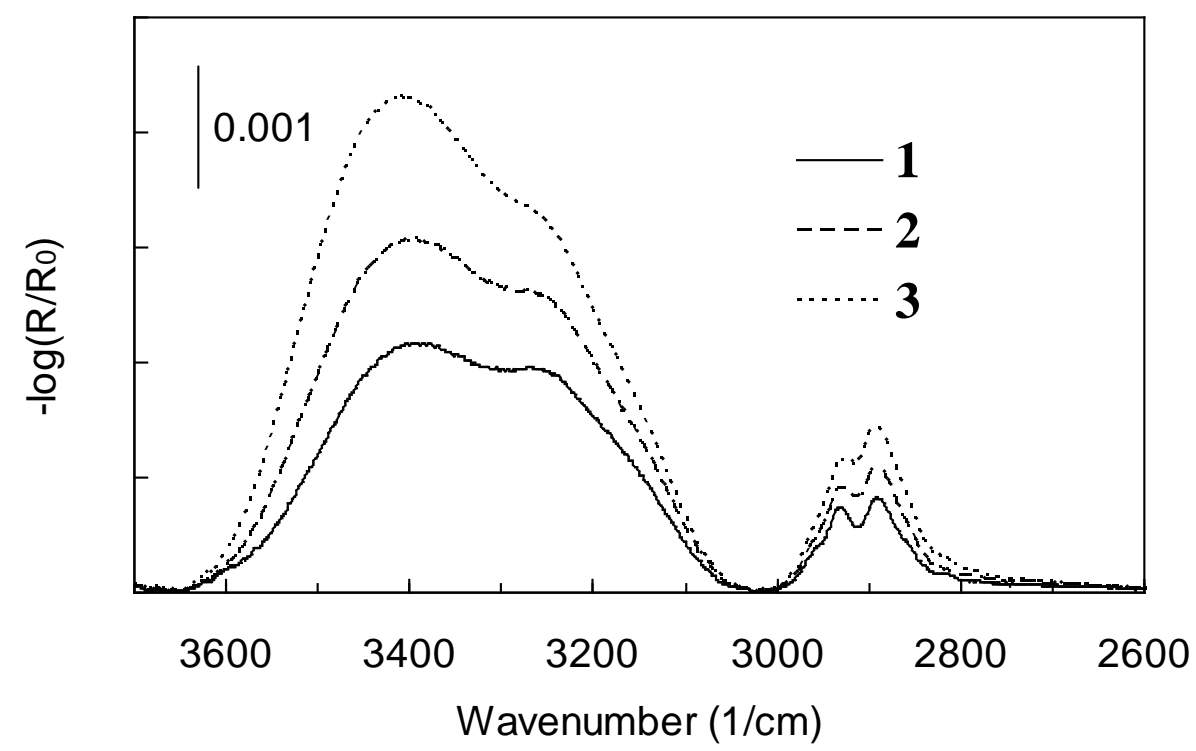

Figure 2. IRAS data in the water $\mathrm{OH}$-stretch and $\mathrm{CH}$-stretch regions for SAMs formed from molecules 1-3.

\subsubsection{IRAS: the $\mathrm{O}-\mathrm{H}$ stretching bands}

Hydrogen bonding of $\mathrm{OH}$-groups in carbohydrates results in a broad absorption around $3300 \mathrm{~cm}^{-1}$. However, the bimodal nature of this band in Figure 2 suggests that the major contribution to the band between 3000 and $3600 \mathrm{~cm}^{-1}$ is from water bound in the film. In the gas phase, the O-H-stretching vibrations of water appear as two well-defined absorptions (symmetric at $3657 \mathrm{~cm}^{-1}$ and anti-symmetric at $3756 \mathrm{~cm}^{-1}$ ), but these broaden into a band over 3000-3600 $\mathrm{cm}^{-1}$ in condensed phases, as a result of variability in the hydrogen-bonding environment. The spectra for the three compounds are similar in shape but differ in intensity; they are dominated by 
a broad peak centered near $3400 \mathrm{~cm}^{-1}$, representing weakly coordinated (or liquid-like) water.[26, 27] All three spectra also have a shoulder around $3230-3240 \mathrm{~cm}^{-1}$, indicating the presence also of tetrahedrally coordinated (ice-like) water, but to a lesser extent,[26, 27] which is in agreement with the hydration structure of fully hydroxylated monosaccharide-terminated SAMs.[21] The absorptions area very strong in this region, indicating that a considerable amount of water is retained in the film, even after drying the samples under a stream of $\mathrm{N}_{2}$ gas, and after purging the spectrometer for 30 min before the measurement commences.

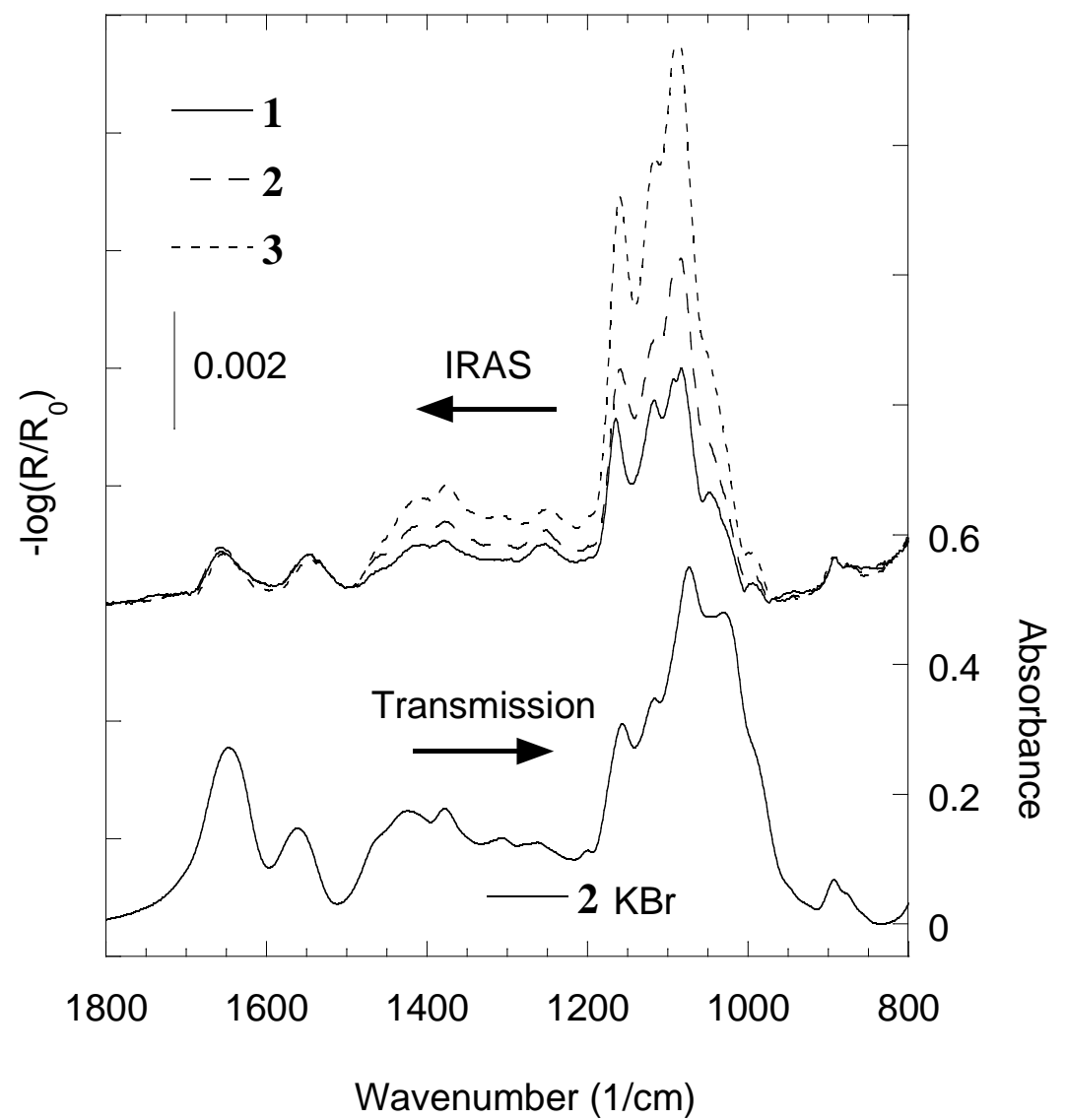

Figure 3. The amide and fingerprint regions of the IRAS spectra for the three tested SAMs (upper set of curves, left axis), and the bulk transmission spectrum for $\mathbf{2}$ (lower curve, right axis). 


\subsubsection{IRAS: the amide bands}

In alkylthiol SAMs, inclusion of amide groups between the alkyl chain and a functional terminating group will stabilize monolayers due to the intramolecular hydrogen bonding between nearby amide groups.[28] Also, the relative intensities of the amide I band (dominated by $\mathrm{C}=\mathrm{O}$ stretching, near $1645 \mathrm{~cm}^{-1}$ ) and the amide II band (C-N stretching, with contributions from C-N-H in-plane bending, approx. $1550 \mathrm{~cm}^{-1}$ ), can be used to determine chain orientation and indirectly also the order in the monolayer. This is accomplished through the surface selection rule, stating that infrared absorption of a vibrational mode near a metal surface depends on the projection of its transition dipole moment on the surface normal. Thus, the observed vibrational intensities depend on the molecular orientation relative to the surface. The combination of amide I and amide II mode intensities, which have their transition dipole moments oriented in mutually orthogonal directions, can thus be used to determine the average tilt of the amide bonds, and also the alkyl segments, in the monolayer. An upright amidecontaining alkyl chain would result in a strong amide II band, and very weak amide I band (where the $\mathrm{C}=\mathrm{O}$ bond is parallel to the surface).[22] The amide band intensities are virtually identical in the three oligosaccharides IRAS spectra, suggesting that the orientation of the amide groups and the alkyl spacer in the SAMs of 1-3 are similar. Figure $\mathbf{3}$ also displays a bulk spectrum of 2, showing the absorption of a randomly oriented sample. Comparing the ratio of amide I and II intensities in the IRAS and bulk spectra, it is clear that there is a considerable suppression of the relative amide I intensity in the IRAS data. This decrease in relative strength of amide I in the SAM strongly supports the interpretation that the molecules form SAMs where the short alkyl chain spacer segments and the C-N bonds adopt a near-upright orientation. 


\subsubsection{IRAS: the fingerprint region}

The frequencies between 950 and $1200 \mathrm{~cm}^{-1}$ include C-O, C-C, C-C-H, and C-O-C vibrational modes of the saccharides. The low-intensity bands extending from $1200 \mathrm{~cm}^{-1}$ up to $1500 \mathrm{~cm}^{-1}$ originate from $\mathrm{H}-\mathrm{C}-\mathrm{O}, \mathrm{C}-\mathrm{O}-\mathrm{H}, \mathrm{C}-\mathrm{C}-\mathrm{H}, \mathrm{C}-\mathrm{C}-\mathrm{O}$ and $\mathrm{CH}_{2}$ bending vibrations. This results in a large number of partially overlapping bands, where exact peak positions and relative intensities depend on saccharide structure, the local environment and, for IRAS, the orientation of the molecules.[20] Detailed interpretation of these bands is very difficult and will not be attempted here. Comparison of IRAS and bulk data shows that the relative intensities of the bands are very different, again a result of different local environments, but notably also the surface selection rule, suppressing and enhancing vibrational IRAS intensities according to their orientation relative to the surface.

The IRAS intensities of these bands increase with the length of the molecules, and even without detailed assignment of the vibrational modes, the intensity may be used to assess the relative amount of saccharide groups on the surfaces. Integration of the bands over the fingerprint area (in the interval 1180-950 $\mathrm{cm}^{-1}$ ) results in relative intensities 0.43:0.61:1 for 1:2:3 (see also Table 1), if normalized to the intensity of 3 (extending the integration to the range $1490-950 \mathrm{~cm}^{-1}$ changes the relative intensities with less than $4 \%$ ). Comparing the integrated fingerprint intensities with the variation in ellipsometric thickness for the SAMs, see Figure 4, the agreement is very good. The close overlap of the three IRAS spectra in the amide region suggests that the surface density of molecules is very similar in all three cases, and also, as was discussed above, that the linker segments have similar averaged conformations. The differences in thickness between the SAMs, with an increase of $5.2 \AA$ from 1 to 2, and 8.9 from 2 to 3, is not quite in agreement with the observed thickness increment of $3 \AA$ per saccharide unit observed in a previous study.[22] 
Considering that the thickness increase does not usually scale linearly with the length of the molecule for SAMs with bulky or irregular functional groups due to variations in packing constraints, molecular tilt, differences in surface density, etc., it is not surprising that the increment deviates from a linear relation. In this case, however, it is notable that the thickness increase from $\mathbf{2}$ to $\mathbf{3}$ is significantly larger than that from $\mathbf{1}$ to $\mathbf{2}$, whereas the reverse situation normally is observed, due to reduced surface density and increasing disorder with increasing molecular size. We suggest that the result in our case is caused by an ordering effect in SAMs formed from $\mathbf{3}$, where the rigid and rod-like properties of $\mathbf{3}$ has a direct influence on the packing in the SAM, resulting in an improvement in molecular order due to larger intermolecular interactions between the saccharide moieties.

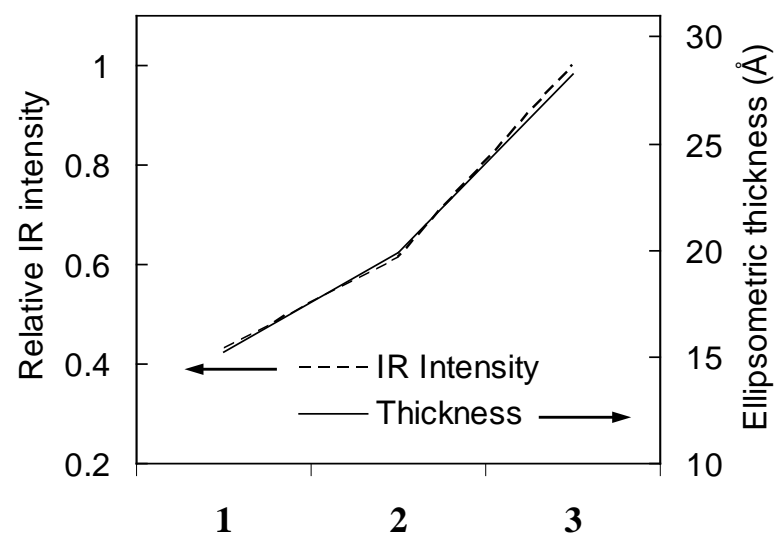

Figure 4. Integrated intensity of the IRAS data in the fingerprint region in the range $1180-950 \mathrm{~cm}^{-1}$ (dashed line, left ordinate), and the ellipsometric thickness (solid line, right ordinate).

\subsection{Immobilization on gold nanoparticles}

Gold nanoparticles (AuNPs) show a pronounced extinction maximum in the visible wavelength range due to localized surface plasmon resonance (LSPR). The resonance conditions, and hence the appearance of the LSPR band, is highly sensitive to changes in the refractive index 
in the vicinity of the particle surface. Spherical 15-nm gold nanoparticles typically show a refractive index sensitivity of $44 \mathrm{~nm} / \mathrm{RIU}$.[29] Aggregation, on the other hand, typically induces a massive red shift and broadening of the LPSR-band. Nanoparticles are subject to Brownian motion and frequently undergo collisions. Weather the particles separate or not after colliding is determined by the balance of attractive and repulsive forces, where van der Waals forces are the main source of attractive interactions. Repulsive forces are primarily provided by charged or polymeric species adsorbed on the particles causing electrostatic and steric stabilization, respectively.

No significant changes in the LSPR bands were observed after a $12 \mathrm{~h}$ incubation of 15-nm citrate-stabilized AuNPs modified with 1, 2, or 3. The functionalized particles (AuNP-1, AuNP-2 and AuNP-3, respectively) were repeatedly centrifuged and redispersed in $10 \mathrm{mM}$ phosphate buffer $\mathrm{pH} 7.4$ with $140 \mathrm{mM} \mathrm{NaCl}$ (PBS) in order to remove unbound molecules. Nonfunctionalized AuNPs aggregate extensively in PBS due to screening of stabilizing charges. AuNP-1 aggregated after the third round of centrifugation whereas AuNP-2 and AuNP-3 demonstrated excellent stability. In order to verify the stability of the particles they were dispersed in PBS with increasing $\mathrm{NaCl}$ concentration. Interestingly, no aggregation was observed even in PBS with $5 \mathrm{M} \mathrm{NaCl}$ for either AuNP-2 or AuNP-3 (Figure 5 a, b), and electrostatic nanoparticle stabilization can thus be ruled out. A similar film thickness is expected on the AuNPs as on the planar gold substrates $(<3 \mathrm{~nm})$, since curvature effects are relatively small on 15-nm particles.[30] Despite the thin film thickness and the low molecular weight of $\mathbf{2}$ and $\mathbf{3}$ they provide excellent steric stabilization, due to their specific anchoring to the nanoparticle surface and favorable interactions with water molecules as was indicated in the IR water absorption bands. The shift in LSPR peak position ( $<1 \mathrm{~nm}$ for both AuNP-2 and AuNP-3) in $5 \mathrm{M} \mathrm{NaCl}$ is smaller than expected indicating that ions do not penetrate to a very large extent into the film. 
The possibility to reduce the stability of the particles by hydrolyzing the carbohydrate chain using $\beta$-galactosidase did not result in any notable changes in the LSPR band (Figure 5c). Presumably the activity of the enzyme was reduced because of the limited accessibility of the $\beta$-glycosidic bonds when the molecules were immobilized on the gold nanoparticles. The observed stability of the nanoparticles would thus not be compromised by hydrolysis when used in diagnostic applications or in vivo. The ability to effectively stabilize nanoparticles, in combination with their small size, excellent anti-fouling properties and biocompatibility, makes these compounds highly attractive for fabrication of hybrid nanomaterials for both diagnostics and therapeutics.

a)

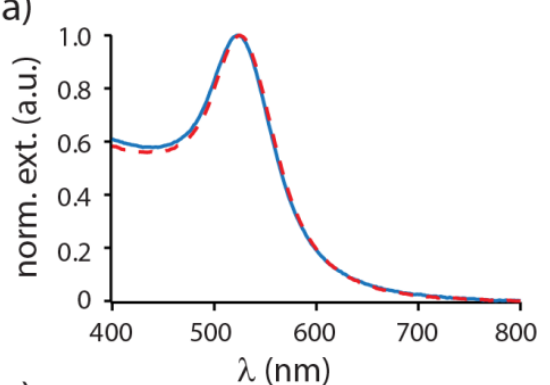

b)
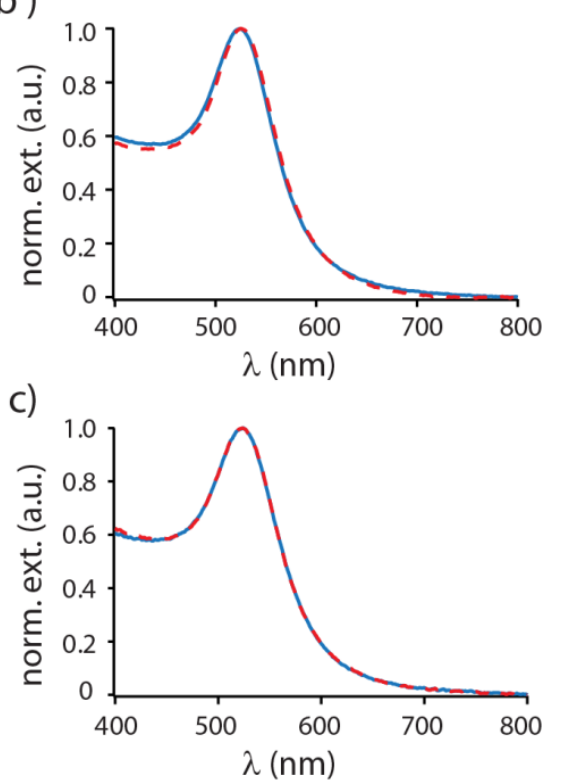

Figure 5. Normalized extinction spectra of (a) AuNP-2 in PBS (solid blue line) and in pH 7.4 buffer with $5 \mathrm{M} \mathrm{NaCl}$ (broken red line). (b) AuNP-3 in PBS (solid blue line) and in pH 7.4 buffer with $5 \mathrm{M} \mathrm{NaCl}$ (broken red line). (c) AuNP-2, before (solid blue line) and after (broken red line) a $15 \mathrm{~min}$ incubation with $0.4 \mathrm{mg} / \mathrm{mL} \beta$-Gal. 


\section{Conclusion}

To conclude, we have synthesized three oligosaccharide-based (di-, tetra-, and hexasaccharide) thiols. For practical applications it is of importance that chemicals are easily available in sufficient quantities; in the described synthesis this is ensured by conversion of readily available lactoside building blocks in only few steps: deprotections, coupling reaction and deprotection. These oligosaccharides have been successfully immobilized into SAMs on gold surfaces and a full characterization is presented. Dispersions of gold nanoparticles, coated with the tetra- and hexasaccharides display excellent stability in concentrated saline solutions, which makes them highly attractive for in vivo diagnostic and therapeutic applications.

\section{Appendix A. Supplementary data}

Supplementary data associated with this article can be found, in the online version, at http://

\section{References}

[1] S.A.W. Gruner, E. Locardi, E. Lohof and H. Kessler, Carbohydrate-based mimetics in drug design: Sugar amino acids and carbohydrate scaffolds, Chem Rev, 102 (2002) 491-514.

[2] A. Guha-Niyogi, D.R. Sullivan and S.J. Turco, Glycoconjugate structures of parasitic protozoa, Glycobiology, 11 (2001) 45r-59r.

[3] C.R.H. Raetz, Biochemistry of Endotoxins, Annu Rev Biochem, 59 (1990) 129-170.

[4] T.K. Lindhorst, Artificial multivalent sugar ligands to understand and manipulate carbohydrate-protein interactions, Springer-Verlag, Heidelberg, 2002.

[5] N.B. Holland, Y.X. Qiu, M. Ruegsegger and R.E. Marchant, Biomimetic engineering of nonadhesive glycocalyx-like surfaces using oligosaccharide surfactant polymers, Nature, 392 (1998) 799-801. 
[6] R. Narain, Engineered carbohydrate-based materials for biomedical applications : polymers, surfaces, dendrimers, nanoparticles, and hydrogels, John Wiley \& Sons, Hoboken, N.J., 2011.

[7] W.M. Watkins and W.T. Morgan, Neutralization of the anti-H agglutinin in eel serum by simple sugars, Nature, 169 (1952) 825-826.

[8] R.A. Dwek, Glycobiology: Toward understanding the function of sugars, Chem Rev, 96 (1996) 683-720.

[9] H.M.I. Osborn, P.G. Evans, N. Gemmell and S.D. Osborne, Carbohydrate-based therapeutics, J Pharm Pharmacol, 56 (2004) 691-702.

[10] K.J. Doores, D.P. Gamblin and B.G. Davis, Exploring and exploiting the therapeutic potential of glycoconjugates, Chem-Eur J, 12 (2006) 656-665.

[11] J.M. de la Fuente and S. Penades, Understanding carbohydrate-carbohydrate interactions by means of glyconanotechnology, Glycoconjugate J, 21 (2004) 149-163.

[12] J.M. de la Fuente and S. Penades, Glyconanoparticles: Types, synthesis and applications in glycoscience, biomedicine and material science, Biochim. Biophys. Acta, 1760 (2006) 636-651.

[13] R. Ojeda, J.L. de Paz, A.G. Barrientos, M. Martin-Lomas and S. Penades, Preparation of multifunctional glyconanoparticles as a platform for potential carbohydrate-based anticancer vaccines, Carbohyd Res, 342 (2007) 448-459.

[14] A.G. Barrientos, J.M. de la Fuente, M. Jimenez, D. Solis, F.J. Canada, M. Martin-Lomas and S. Penades, Modulating glycosidase degradation and lectin recognition of gold glyconanoparticles, Carbohyd Res, 344 (2009) 1474-1478.

[15] O. Martinez-Avila, K. Hijazi, M. Marradi, C. Clavel, C. Campion, C. Kelly and S. Penades, Gold Manno-Glyconanoparticies: Multivalent Systems to Block HIV-1 gp120 Binding to the Lectin DC-SIGN, Chem-Eur J, 15 (2009) 9874-9888.

[16] J. Gao, X. Huang, H. Liu, F. Zan and J. Ren, Colloidal Stability of Gold Nanoparticles Modified with Thiol Compounds: Bioconjugation and Application in Cancer Cell Imaging, Langmuir, 28 (2012) 4464-4471.

[17] Y.L. Liu, M.K. Shipton, J. Ryan, E.D. Kaufman, S. Franzen and D.L. Feldheim, Synthesis, stability, and cellular internalization of gold nanoparticles containing mixed peptidepoly(ethylene glycol) monolayers, Anal Chem, 79 (2007) 2221-2229.

[18] V.P. Torchilin, Recent advances with liposomes as pharmaceutical carriers, Nat Rev Drug Discov, 4 (2005) 145-160.

[19] M.F. Schneider, G. Mathe, M. Tanaka, C. Gege and R.R. Schmidt, Thermodynamic properties and swelling behavior of glycolipid monolayers at interfaces, J Phys Chem B, 105 (2001) 5178-5185.

[20] M. Hederos, P. Konradsson and B. Liedberg, Synthesis and self-assembly of galactoseterminated alkanethiols and their ability to resist proteins, Langmuir, 21 (2005) 2971-2980.

[21] T. Ederth, T. Ekblad, M.E. Pettitt, S.L. Conlan, C.X. Du, M.E. Callow, J.A. Callow, R. Mutton, A.S. Clare, F. D'Souza, G. Donnelly, A. Bruin, P.R. Willemsen, X.J.J. Su, S. Wang, Q. Zhao, M. Hederos, P. Konradsson and B. Liedberg, Resistance of Galactoside-Terminated Alkanethiol Self-Assembled Monolayers to Marine Fouling Organisms, Acs Appl Mater Inter, 3 (2011) 3890-3901.

[22] T. Fyrner, H.H. Lee, A. Mangone, T. Ekblad, M.E. Pettitt, M.E. Callow, J.A. Callow, S.L. Conlan, R. Mutton, A.S. Clare, P. Konradsson, B. Liedberg and T. Ederth, SaccharideFunctionalized Alkanethiols for Fouling-Resistant Self-Assembled Monolayers: Synthesis, Monolayer Properties, and Antifouling Behavior, Langmuir, 27 (2011) 15034-15047. 
[23] T. Fyrner, S.C.T. Svensson and P. Konradsson, Synthesis of tri-, penta-, and heptasaccharides, functionalized with orthogonally N-protected amino residues at the reducing and non-reducing ends, Tetrahedron, 68 (2012) 6712-6720.

[24] H.E. Gottlieb, V. Kotlyar and A. Nudelman, NMR chemical shifts of common laboratory solvents as trace impurities, J Org Chem, 62 (1997) 7512-7515.

[25] L. Liu, M. Rozenman and R. Breslow, Hydrophobic effects on rates and substrate selectivities in polymeric transaminase mimics, J Am Chem Soc, 124 (2002) 12660-12661.

[26] Q. Du, E. Freysz and Y.R. Shen, Vibrational-Spectra of Water-Molecules at Quartz Water Interfaces, Phys Rev Lett, 72 (1994) 238-241.

[27] J. Kim and P.S. Cremer, IR-Visible SFG investigations of interfacial water structure upon polyelectrolyte adsorption at the solid/liquid interface, J Am Chem Soc, 122 (2000) 12371-12372. [28] R. Valiokas, M. Ostblom, S. Svedhem, S.C.T. Svensson and B. Liedberg, Thermal stability of self-assembled monolayers: Influence of lateral hydrogen bonding, J Phys Chem B, 106 (2002) 10401-10409.

[29] H.J. Chen, X.S. Kou, Z. Yang, W.H. Ni and J.F. Wang, Shape- and size-dependent refractive index sensitivity of gold nanoparticles, Langmuir, 24 (2008) 5233-5237.

[30] H.D. Hill, J.E. Millstone, M.J. Banholzer and C.A. Mirkin, The Role Radius of Curvature Plays in Thiolated Oligonucleotide Loading on Gold Nanoparticles, Acs Nano, 3 (2009) 418-424. 